\title{
A theory-driven framework for the study of language in business
}

\author{
Tatiana A. Shiryaeva - Ariuka I. Gelyaeva - Rashid S. Alikaev - Dzhamilya \\ Dzh. Huchinaeva - Mirrat R. Toguzaeva
}

DOI: $10.18355 /$ XL.2018.11.01.08

\begin{abstract}
A conceptual framework examines how language influences the way businessmen interact in their professional setting. The linguistic aspects of socio-cognitive modeling as the methodological basis for the contemporary business discourse analysis are in the center of the paper. The authors point out the main approaches to establishing the correlation between the cognitive activity of businessmen and the knowledge representation which is concentrated in the language of this social institute; the authors develop an original complex linguistic model of the business discourse that makes it possible to single out and explain cognitive and discursive mechanisms of how business knowledge acquires a linguistic form and to clarify the role of the language in the process of categorization and conceptualization of the business world. Moreover, taking into account the maturity of the linguistic assessment models, this paper puts forth a new linguo-cognitive model which solves the problem of the narrow-subject directives when studying the linguistic aspects of business communication thus helping to shift from the particular case of language research to a broader study of linguistic and cognitive mechanisms of an institutional discourse.
\end{abstract}

Key words: sociolinguistics, pragmatics, business language, business discourse, linguistic model, language conceptualization, thesaurus, text, linguistic concept

\section{Introduction}

Modern business relies heavily on language. In any business activity, effective results can only be achieved through effective use of different linguistic means. We rarely encounter any business dealing with texts that's why the process of communication within the business society evokes the vivid interest of every branch of liberal arts and in particular that of linguistics. Close study of linguistic mechanisms in business discourse (further on "BD") from the standpoint of linguistics is necessitated by both extralinguistic and linguistic factors. Extralinguistic factors include rapid penetration of business into every aspect of human life and the fact of it being one of the most important phenomena of the modern society. Experts agree on the idea that "business relations today belong to the key mechanisms of the civilization and the new economic and social conditions bring out the need to raise the level of communicative competences of every member of the business community" (Bargiela-Chiappini, 2007: 19). It is obvious that effective use of different linguistic means is crucial for business success as it is both the platform for various kinds of interaction between people in numerous professional contexts and one of the "most dynamic discursive spheres of the current communication field" (Grant, 2004: 32).

In terms of linguistics, business discourse seems to be an extremely interesting subject for study, as the research of its language paradigm and the system of interaction of various linguistic levels in the process of professional communication is still in the initial research stage. There is more linguistic research on the European traditions of intercultural negotiations studies and language analysis at work. At the lexical level, there have been studies of specific morphological features to construct meanings in business. Different morphological variations represent efforts of business representatives in persuading people to accept unique business vocabulary. At the syntactic level, different syntactical peculiarities demonstrate the importance of the role played by syntax in different business interactions. At the semantic level, quite a 
lot research has been carried out to distinguish the metaphor participation in BD. Nowadays BD attracts specialists from the various fields of linguistics, pragmatics and the discourse of analysis. It is necessary to agree with the opinion of D. Grant (2004: 21), who argued that "DD is a polysemantic term that includes various concepts, research traditions, and scientific approaches."

It is important to note that despite the sufficient number of existing scientific publications devoted to morphological, lexical, sociolinguistic, textual, structural, discursive and many other parameters of business communication, "the study of business discourse today has major gaps, the most important of which is the lack of a holistic conception of this sphere of communication as well as the lack of a universal and full theory of business discourse able to explain the main linguistic aspects of meaning making and speech interaction among modern business representatives" (Shiryaeva, 2014: 11; Galushkin, 2015). The special nature of the business discourse requires, in our view, a conceptual framework examines how business language influences the way businessmen interact and comprehend each other, the linguistic means of common sense-making.

What makes things more complicated is the fact that the creation of a universal scientific conception of the business discourse faces an essential problem - that of defining the very term "discourse", giving it a universal meaning or at least distinguishing the preferred tendencies of its definition - which at the current stage of linguistics seems hardly possible. Furthermore, it is doubtful that there is a definition among the widely used ones that can be considered preferable. There are numerous approaches to studying the nature of discourse. However, not one of them can be considered singularly "correct." Plenty of scientific approaches to such a complicated phenomenon are aimed to research various aspects of it and to achieve analytical objectives, which scientists fulfill with a varying degree of success. In addition to this, "different scientific methods sometimes lead to the same conclusion by using various terms and instruments, which belong to one "micro-community" of researchers or the other" (Dridze, 1984: 6). Discourse, as the researchers unanimously agree, can be studied on the basis of different parameters, signs, and characteristics which simultaneously exist in it, and it should be viewed as a complex phenomenon, as a "materialized result of mental and speech activity of people" (Gluhov, Kovshikov, 2007: 38).

\section{Research Methodology}

It seems to us that the creation of a coherent and systematic conception of the modernday business discourse is possible, on the one hand, according to the principle of anthropocentrism within the research reference points "a person-a profession-a text" and with the help of scientific research tools of cognitive linguistics, pragmatics and sociolinguistics, and on the other hand, via the employment of a wide range of empirical material belonging to different system languages. We believe the sociocognitive modeling to be an effective methodological basis for studying the business discourse. It is aimed at overall and in-depth research of cognitive and discursive mechanisms of how knowledge belonging to the sphere of business acquires a linguistic form, and at defining the role of the language in the process of categorization and conceptualization of the business world. Moreover, such kind of modeling, in our view, enables scientists to reveal and analyze the system of particular frames which relate to the particular field of a person's experience and are verbalized through lexical units that nominate objects and the reality of the business world and reflect systematic connections between the latter. We believe socio-cognitive modeling to be the way to "reach a deeper understanding of interiorized language and come closer to solving the problem of modeling linguistic abilities of a human being"

XLinguae, Volume 11 Issue 1, January 2018, ISSN 1337-8384, eISSN 2453-711X 
(Yokoyama, 2005: 121). This method also makes it possible to explain the process of knowledge formation in the course of communication.

In the last decades the concepts "model" and "modeling" have been widely used in the broadest range of various linguistic studies. Modeling as a way of constructing and recreating real objects, processes, and phenomena acquire an increasingly epistemological nature and become a synonym to the process of cognition. As a rule, when speaking about the linguistic models, researchers mainly bring up $\mathrm{N}$. Chomsky's (1986) and his like-minded colleagues' theories of syntactical structures that, according to them, are the basic model for generating sentences.

It is impossible not to notice the growing tendency of conducting studies that proclaim modeling to be the main scientific method of linguistic research: many different models that have recently came to life concentrate on the special cases of a language and cultural reality, which indicates the fact that "the geography of philological problems has become recognizably more detailed" (Belousov, 2010: 95); applied linguistics is also developing rapidly and a great number of applied linguistic models is elaborated within its framework in both traditional computer linguistics, which is aimed at speech detection and text processing, automated translation and creation of the new search engines, and in relatively new linguistic areas, such as jurislinguistics, political linguistics, business linguistics and so on. All of these works share the same idea: the devised models have a solid explanatory potential, they serve as an explicit confirmation of various hypotheses and are characterized by having a comprehensive character (Alvesson, 2000; 1128). We should stress that the method of linguistic modeling is currently used not only in the endeavors of structuring knowledge, represented by various linguistic devices but also in defining the meaning structure of the model.

Another important proposition for this study is that "social reality can be viewed as a theoretical construct of different scientific branches" (Schiffrin, Tannen, Hamilton, 2004: 251), including linguistics. From the standpoint of the latter, any social reality is the result of categorization and nomination of a cluster of objects: the language, the linguistic picture of the world, the language game, the language politics, the linguistic personality, the linguistic ability, the linguistic context, the linguistic competence, etc. Each of these terms, to our mind, is something more than just a sum of all the components and speech and cognitive activities performed by an individual that together constitute the abovementioned notions. It is obvious that in order to be heard and understood any person using the language has to know the values, intentions, and conventions which exist in a particular society. It is the society that predefines the language that is used within it, but the language employed in this society also shapes and structures it.

Considering our main goal - that of constructing a comprehensive model of the business discourse, we believe it is essential to give answers to at least three conceptual questions, namely:

- What is the business discourse in its essence?

- What does the process of modeling the business discourse look like? (And why this type of discourse is modeled this way and not the other?)

- What are the expected results of such kind of discourse modeling?

We believe the answers to these questions to be the very fundamental basis that the universal conception of the modern business discourse should rely on. The main advantage of this model is the ability to define and explain the role of linguistic structures during the process of mental perception and speech production of the members belonging to the modern-day business community. In our view, sociocognitive modeling is based on admitting the fact that any linguistic form is the representation of a cognitive structure. There is a certain correlation between the linguistic and cognitive structures: 
1. As a semiotic system, a language reflects the real mental activities of a human being in the form of numerous combinations of signs. In other words, a language is a system of signs that encodes and transforms information in a specific way;

2. Human consciousness is structured not only via the perception process of the surrounding world and the results of a person's activity but to a considerable degree by the language and systematic relations within it. In other words, a language functions as the key to reaching mental processes, which can be explained by the fact that that the way of thinking and overall experience of the mankind are concentrated exactly in the language.

From the standpoint of socio-cognitive modeling the business discourse is a relatively complex phenomenon that "possesses a number of institutional parameters and cognitive linguistic characteristics, which distinguish it from any other type of institutional discourse" (Karasik, 2009: 134).

In general the business discourse that we define as "the status and role activity of speech production and mental processes belonging to people who are necessarily involved in professional business relations, which, in turn, are based on regulations, norms and communication rules commonly accepted in the business world" (Shiryaeva, 2006: 92), demonstrates, in our view, two major characteristics essential for understanding its nature and revealing its creation and function mechanisms:

1. the discourse is identified with mental and communication processes that take place in the brain of the representatives of a certain social institute - the professional business community;

2. the relationships between the users of this discourse are moderated by the universal rules of business communication.

If we interpret the business discourse this way, we have to admit that initially it is a certain communication structure with domains, in the heart of which there is professional communication of business representatives, while the periphery is constituted by the communication of non-professionals - people who do not belong to the business sphere and are just language users.

\section{Results and Discussion}

\section{Institutional nature of the business discourse as the basis for its modeling}

There is no doubt that one of the key points of modeling the BD is its inherent institutional nature. This is proved by the thesis that any verbal interaction within the professional business activity is predefined by certain social associations accepted in this institute, by regulations and status abilities which are set in this sphere. In other words, the direct dependence of the business discourse on the social institute is caused, first of all, by the professional sphere that the communicating parties belong to, by their social identification as well as by the specifics of the communication setting. It should be stressed that the institutional characteristics bring forward specific communication goals, communication roles of the participants (that of an agent and client), the social space, a specific chronotope typical of this discourse, symbolic behavior of the discourse participants, some certain communication strategies and a unique picture of the world (Shiryaeva, 2013: 824). These characteristics also condition the structure of the texts, including the rules of their composition and the sequence of their parts, e.g., contracts, interviews, reports, board meetings, articles in mass media. As a result words within the business community act as a unique communication tool.

So, the business discourse is the result of a particular social institute (in this case of the business community), within which "the discourse is an integral part of social and production relationships as it both forms these relationships and is formed by them" (Djik, 1977: 64). This type of institutional discourse offers a plethora of specialized

XLinguae, Volume 11 Issue 1, January 2018, ISSN 1337-8384, eISSN 2453-711X 
communicative cliché models for people, who not being acquainted; have to communicate according to the norms of the modern-day business community. As a heterogeneous phenomenon, the BD includes a number of subtypes and is also characterized by having certain social role peculiarities as well as communicative, structural and semantic traits. We should point out that the social institute of business determines and structures the profession related way of thinking of the business world participants, it shapes their whole system of knowledge and the system of speech patterns which verbalize this knowledge and are stored and produced within the business community of today.

Business penetrates almost every aspect of social activities and lies in the heart of practically every communication situation that is produced by the current social environment. Every business community member perceives and understands his or her professional activity through the language. "A language is the top of an enormous iceberg. When we use a language, we inevitably rely on immense cognitive resources that evoke endless frames and models in our consciousness" (Fauconnier URL: http://terpconnect.umd.edu/ israel/Fauconnier-MentalSpaces.pdf). At the same time, the current business discourse which serves the Institute of business is accessible both to the members of the business community and to people who have to get involved in this sphere for one reason or another. The BD turns out to be "a complete and a multilevel linguistic system" (Chafe, 2004: 680) of interaction between an addresser and an addressee who are crucial information components of the business discourse, and of the text that appears to be the result of their communication.

\section{Structural and semantic paradigm of the global frame of the modern business discourse}

There is no doubt about the fact that successful implementation of business communication presupposes the knowledge of a conceptual system which includes perception, skills values, and norms that belong to both formal and informal business activity as well as the knowledge of the certain rules of business communication shared by all businessmen. Such system of knowledge (both universal and professional) makes up the basis for the multi-level professional and conceptual picture of the world which is implemented via the global frame of the BD which includes corresponding institutional frames. It is verbalized through specific discursive models, formulas, special thesaurus and the system of profession-related texts at the linguistic, cognitive and discursive levels.

The global frame of the modern business discourse represents professional consciousness which according to E.F. Tarasov (1989: 26), “.... is the combination of mental images formed and represented with the help of language tools such as words, free and set expressions, sentences, texts and association domains." We believe that the creation of a global frame of the modern business discourse requires identification and analysis of numerous interrelated, interdepend and mutually influenced models which represent mental and speech interaction of the business community members. Such a frame, in our opinion, has to not only characterize all cognitive occurrences of the BD in a systematic way, but also to reveal the connections between the texts of the business discourse, the context of professional interaction at the level of social activity, and the social knowledge that is integrated into the text processing.

The results of the conducted research demonstrate that the multi-level structure of the business discourse includes three basic types of frames: the key (upper) frames BUSINESS, institutional frames - ECONOMICS, MANAGEMENT, FINANCE, MARKETING, ENTREPRENEURSHIP, POWER, and derivative (peripheral) frames which altogether represent the linguistic picture of the world of the modern-day business community.

The key concept of the BD is the linguistic and cultural concept "BUSINESS" which is a big value in the modern cognitive and discursive space. The concept 
"BUSINESS" becomes the "key figure in the world picture for a modern businessman and tops the hierarchy of other language units, knowledge, and meanings" (Kubryakova, 2008: 9). At the same time in some particular situations, this concept can partially or fully lose its common language semantics, acquire individual shades of meaning and connotations, change its subject reference, etc.

Being the process of creative compliance with the norm which is determined and perceived through the complex and multi-level professional picture of the world, the business discourse is based on the system of institutional frames. We believe the institutional frames to be the system of professional, business-related knowledge, organized according to the principle of "from general to specific," stored in the memory of every member of the business community, along with the skill of applying this knowledge in the process of business communication. Institutional frames of the BD ECONOMICS, MANAGEMENT, FINANCE, MARKETING, ENTREPRENEURSHIP, POWER represent a structured system of knowledge and a hierarchical structure of the mental and speech activity that every businessman possesses. Each of the identified frames carries a certain "quantum" of knowledge which is regularly implemented and has a structuring origin. They unpack, expand and clarify the content of the keyframe.

Every institutional frame is a special way of presenting and structuring professional information as well as reaching its ultimate explication, special stratification, and regulated usage, etc. The combined system of institutional frames moderates the actions of the business community members in a certain way and allows them to adequately interpret utterances and behavior of their colleagues. It is possible to single out the elements of the upper level within each institutional frame. As a rule, they include the names of situations which are most common for the entire business community.

The universal upper levels in the structure of each institutional frame are "management," "competition," "labor resources," "business development," "adaptation," "partnership," i.e., those dominant constants that are intrinsic to business discourse. These constants play a crucial role in the professional work of modern business society and have a key position in the language worldview of the modern business world, which is predetermined by a vast diversity of their linguistic representation. In addition to that, these dominant constants are also of certain importance in terms of forming special business discourse characteristic, as well as such business discourse categories as information structure and its institutional nature. The lower level elements include specific data, closely connected to a certain aspect of professional work, which is verbalized in the text commonly with the use of other institutional frames. These slots serve as terminal nods, connecting the mentioned frame with other business discourse frames.

Due to the complexity performed by a conceptualized fragment of professional reality, professional frames are differently actualized in business discourse with the help of, especially segmented texts. In should be mentioned, that the text, representing business discourse institutional frames, becomes the result of both cognitive and speech activity.

Business discourse participants are immersed in a constant speech flow, and, thus, in a continuous production and understanding process of different text types with the help of specific business discourse thesaurus.

Business discourse thesaurus demonstrates professionally-oriented knowledge, values, notion systems, generally accepted ideas and concepts. In other words, this thesaurus is a linguistic representation of institutional frames. Being a linguistic analog of certain real-world fragments, business discourse thesaurus is relatively constant and specific in terms of its contents; represents logically connected subjects and

XLinguae, Volume 11 Issue 1, January 2018, ISSN 1337-8384, eISSN 2453-711X 
phenomena of professional work; actualizes all the cognitive models of business discourse participants in the real situations of professional communication.

The abovementioned thesaurus is determined by the language worldview, as well as certain peculiarities of everyday professional work, and is used by all the participants in the modern business. Moreover, this modern business community thesaurus reflects a set of social, cognitive, semantic and linguistic language structures.

The suggested socio-cognitive model of the BD is a dynamic model which determines the mechanism of the business discourse production and understanding. It is a complex multi-level model of the mental origin which reflects the way of conceptual organization of knowledge within the business community. Invariant elements of the business discourse - an addresser, an addressee, and a text - are the basis for business stability, as for the variable elements, such as institutional frames, types of texts, metaphorical and metonymical models, they embody the dialectical character of communication, the possibility of professional interaction of the business sphere participants as well as offer the business discourse system a potential for growth. This model is aimed to solve the problem of the narrow-subject directives when studying the language aspects of business communication thus helping to shift from the particular case of language research to a broader study of linguistic and cognitive mechanisms of institutional discourse.

\section{Conclusion}

Taking into consideration the anthropologically predetermined necessity to elaborate general discourse theory (including business discourse), along with fundamental paradigm changes in modern linguistics and the accumulated experience in terms of human language interpretation, we can safely conclude that a socio-cognitive approach to business discourse modelling allows us to establish an evident connection between the businessmen's cognitive activity and the representation of knowledge, stored in the language by the business community. In our opinion, such an approach helps to overcome the narrow subject directives in business communication linguistic research and permits to pass from a specific language analysis to the investigation of general linguo-cognitive mechanisms of institutional discourse types. The offered integrated and methodologically coherent model of modern business discourse within the framework of cognitive-discursive paradigm (with anthropocentrism and explanatory ability as its main principles) may lead to the solution of such an acute problem as the role of language in conceptualization and categorization processes of different social institutions.

\section{Bibliographic references}

ALVESSON, M. - KARREMAN, D. 2000. Varieties of Discourse: on the study of organizations through discourse analysis. In: Human Relations, vol. 53, n. 9, pp. 1125-1149. ISSN 0018-7267 (Print) 1573-9716 (Online)

BELOUSOV, K. I. 2010. Model linguistics and the problem of language reality modeling. In: Bulletin of the Orenburg State University, n.11, pp. 94-96. ISSN 1814 6457.

BARGIELA-CHIAPPINI, F. 2007. Business Discourse. Basingstoke: Palgrave Macmillan. ISBN 978-1-137-02493-0.

CHAFE, W. 2004. The analysis of discourse flow. In: The handbook of discourse analysis. Oxford: Blackwell Publishing Ltd, pp. 673-687. ISBN 9780631205951.

CHOMSKY, N. 1986. Knowledge of language: its nature, origins and use. London: Praeger. ISBN 0-275-91761-4.

DIJK,T.A. van. 1977. Text and Context. Explorations in the Semantics and Pragmatics of London: Longman. 261 p. ISBN D-582-291D5-4.

DRIDZE, T. M. 1984. Text activity in the structure of social communication. Problems of semiosociopsychology. Moscow: Nauka. 
GALUSHKIN, A. 2015. Internet in modern Russia: History of development, place and role. In: Asian Social Science, vol. 11, n. 18. pp. 305-310. ISSN 1911-2017 (Print) ISSN 1911-2025 (Online)

GLUHOV, V. - KOVSHIKOV, V. 2007. Psycholinguistics. The theory of speech activity. Moscow: Izd-vo: AST. ISBN 5-17-040766-1.

GRANT, D. [et. al.]. 2004. Introduction: Organizational Discourse: Exploring the field. In: The SAGE Handbook of Organisational Discourse. London: Sage, pp. 1-36. ISBN 0761972250.

FAIRCLOUGH, M. 1989. The discourse on language. In: The archaeology of knowledge \& The discourse on language. - New York: Pantheon Books, pp. 215-237. FAUCONNIER, G. - TURNER, M. 2002. The Way We Think. New York: Basic Books.

KARASIK, V. I. 2009. The Language keyses. Moscow: Gnozis. ISBN 978-5-94244030-5

KUBRYAKOVA, E.S. 2008. Towards a definition of the image concept. In: Questions of Cognitive Linguistics, n. 2, pp.5-11. ISSN 1812 -3228.

KUBRYAKOVA, E.S. 2001. Reflections on the fate of cognitive linguistics at the turn of the century. In: Questions of Philology, n.1, pp.39-49. ISSN 1562 -1391.

PRIKHODKO, A. N. 2009. The concept in discourses vs concepts in the discourse. In: Discourse, concept, genre: the collective monograph. Nizhny Tagil: NTGSPA, pp.125-139.

TARASOV, E. F. 1989. The problems of study, description and modeling of speech communication. In: Linguistic pragmatics and communication with computers. Moskow: Nauka, pp. 5-34.

SCHIFFRIN, D. - TANNEN, D. - HAMILTON, H. 2004. The handbook of discourse analysis. Oxford: Blackwell Publishing Ltd. DOI: 10.1017/S0022226703292367. ISBN-13 978-0470670743

SHIRYAEVA, T. A. 2006 The Cognitive model of business discourse. Pyatigorsk: PGLU. ISBN 5-89966-664-1

SHIRYAEVA, T. A. 2013. Modern business discourse: the experience of linguocognitive research. In: Cognitive language research, vol. XIII, pp. 820-831. ISSN 2071-9639.

SHIRYAEVA, T. A. 2014. Structurally-substantial and functional paradigm of modern business discourse. PhD Thesis: Nalchik.

YOKOYAMA, O. B. 2005. Cognitive model of discourse and Russian word order. Moscow: Publishing house Languages of Slavic culture. ISBN 5-9551005-7-1.

Words: 4515

Characters: 30821 (17,12 standard pages)

Prof. Tatiana A. Shiryaeva, Dr. Philol.

Department of English language and professional communication

Pyatigorsk State University

Kirov str. 63

357502 Pyatigorsk

Russia

shiryaevat@list.ru

Prof. Ariuka I. Gelyaeva, Dr. Philol.

Department of General linguistics and Russian language

Kabardino-Balkarian State University

named after H. M. Berbekov

Chernyshevskogo str. 173

XLinguae, Volume 11 Issue 1, January 2018, ISSN 1337-8384, eISSN 2453-711X 
360004 Nalchik

Russia

gariuka@mail.ru

Prof. Rashid S. Alikaev, Dr. Philol.

Department of German and Roman philology

Kabardino-Balkarian State University named after H. M. Berbekov

Chernyshevskogo str. 173

360004 Nalchik

Russia

ralikaev@mail.ru

Assoc. Prof. Dzamilya Dzh. Huchinaeva, PhD

Kabardino-Balkarian State Agrarian University

Department of Foreign languages

Lenin avenue 18

360030 Nalchik

Russia

gjjamilia@mail.ru

Assoc. Prof. Mirrat R. Toguzaeva, PhD

Department of Foreign languages

Kabardino-Balkarian State University named after H. M. Berbekov

Chernyshevsky Str. 173

360004 Nalchik

Russia

mirra_alikaeva@mail.ru 